\title{
SPECTROSCOPY OF RADIATION TRAPS IN Si BY TEMPERATURE DEPENDENT PHOTOCONDUCTIVITY AND GENERATION CURRENTS
}

\author{
E. Gaubas, T. Čeponis, J. Pavlov, A. Velička, and V. Kalesinskas \\ Institute of Applied Research, Vilnius University, Sauletekio 9-III, LT-10222 Vilnius, Lithuania \\ E-mail: eugenijus.gaubas@ff.vu.lt
}

Received 31 July 2013; revised 14 October 2013; accepted 4 December 2013

\begin{abstract}
An analysis of excess carrier decay transients has been performed on the reactor neutron irradiated Si n-type material grown by the magnetic field applied Czochralski (MCZ) technology, using the microwave-probed photoconductivity (MW-PC) transient technique. The measurements of temperature dependent excess carrier lifetime variations were carried out on the just irradiated and annealed samples in order to identify the prevailing radiation defects and to predict trap behaviour under thermal treatments. The activation energy of the dominant carrier traps has been extracted. Barrier capacitance and generation current variations in neutron irradiated MCZ Si pin diodes have been controlled employing the barrier evaluation by the linearly increasing voltage (BELIV) technique, as well.
\end{abstract}

Keywords: spectroscopy of carrier traps, photoconductivity transients, carrier lifetime, generation current

PACS: 72.40.+w, 29.40.-n, 78.60.-b

\section{Introduction}

Particle detectors based on Si pin structure are commonly employed in high energy particle experiments for rapid and reliable detection of high energy particles [1. 2]. However, large density of radiation induced defects acting as carrier traps affect the detector functional parameters by reducing the charge collection efficiency [1, 2], increasing the leakage current [1-3], and consequently modifying the pulsed transient waveforms [ $1-$ 4. This necessitates a deeper study of peculiarities of carrier recombination channels attributed to radiation defects of large density. Carrier thermal generation and trapping parameters are the most important in evaluation of the performance of particle detectors operating at high fluences. Therefore, new techniques are desirable for the reliable ex situ and in situ spectroscopy of large density traps when traditional methods, such as deep level transient spectroscopy (DLTS), become non-applicable. Determination of the spectral signatures (such as activation energy, capture cross-section, etc.) of the dominant radiation traps and of their variations during irradiation is important in order to clarify the main reasons of the degradation of particle detectors under heavy irradiations. This is also relevant in search of methods for the enhancement of radiation tolerance of particle detectors.
In this work, barrier capacitance, carrier recombination, generation and trapping parameters have been studied employing the barrier evaluation by linearly increasing voltage (BELIV) [5] and microwave probed photoconductivity transient (MW-PC) [6] techniques. A study of temperature dependent excess carrier lifetime variations has been carried out on the just irradiated and annealed samples in order to identify the prevailing radiation defects and to predict trap behaviour under thermal treatments. An analysis of temperature dependent generation current and carrier lifetime has been performed in order to evaluate activation energy of carrier recombination as well as trapping centres and to identify the dominant radiation defects. Spectroscopy and identification of the prevailing radiation defects is important to predict operational characteristics of the future detectors for high luminosity colliders.

\section{Samples and measurement techniques}

A set of n-type $\mathrm{Si}$ of high resistivity $\left(N_{\mathrm{D}} \sim 10^{12} \mathrm{~cm}^{-3}\right)$ wafer samples grown by the magnetic field applied Czochralski (MCZ) technique and pin diodes [⿰亻] with an active area of $5 \times 5 \mathrm{~mm}^{2}$ and thickness of $300 \mu \mathrm{m}$, made of the same material, have been examined. These samples were irradiated with reactor neutrons of fluence $\Phi\left(1 \mathrm{MeV}\right.$ eq.) $10^{14} \mathrm{n} / \mathrm{cm}^{2}$. The surfaces of wafer 
samples were passivated with thermal oxide. The isochronal anneals for $24 \mathrm{~h}$ were performed by varying heat treatment temperature in the range of $80-380{ }^{\circ} \mathrm{C}$ for wafer samples. Wafer samples were employed for analysis of carrier recombination and trapping/generation parameters, while diode samples were used to evaluate carrier generation characteristics.

Temperature dependent excess carrier decay transients have been examined by the MW-PC technique [6] modified by usage of the special cryostat. This cryostat has been designed for the precise positioning of the optical fibre-tip and needle-tip MW probes in vacuum. Also, this cryostat is supplied with the $\mathrm{CaF}$ window for additional bias illumination of a wide spectrum. The sample is commonly mounted on a cold finger cooled by liquid nitrogen. The liquid nitrogen flow is manipulated for precise temperature stabilization. Temperature control is performed on a cold finger and the sample. Excess carriers are photo-generated by $500 \mathrm{ps}$ laser pulses of $1062 \mathrm{~nm}$ wavelength. The excitation light is transferred into the cryostat by using an optical fibre. The fibre-tip light spot excited area of the sample is probed by microwaves of $22 \mathrm{GHz}$ using a needle-tip antenna. The microwave radiation is supplied to the needle-tip antenna by using the coaxial cables and vacuum proof connectors. The excess carrier decay transients are recorded by a $1 \mathrm{GHz}$ digital Tektronix oscilloscope TDS-5104.

Barrier capacitance and generation current transient measurements are implemented by using the BELIV technique [5, 8]. The BELIV measurement circuit consists of a sample which is connected in a series with a $50 \Omega$ load resistor and a generator of linearly increasing voltage (LIV). Transients are measured on a $50 \Omega$ load resistor and recorded by the same $1 \mathrm{GHz}$ digital oscilloscope TDS-5104. The temperature dependent BELIV pulsed transients are examined by mounting the sample on the cold finger of the liquid nitrogen cryostat supplied with special electrodes. The MW-PC and BELIV transients have been measured in the temperature range of $100-300 \mathrm{~K}$.

The in situ measurements of barrier capacitance and generation current transients were performed at room temperature during irradiation by $25 \mathrm{MeV}$ spallator-type neutrons at Louvain la Neuve University [9].

\section{Experimental results and discussion}

The creation of radiation defects was controlled by in situ measurements [ 4 ] of variations of the BELIV transients during irradiation by spallator neutrons. The evolution of BELIV transients is illustrated in Fig. 1(a). The transients for a reverse biased junction are composed of barrier capacitance charging $i_{C}(t)$ (as the initial phase of the BELIV transient) and generation $i_{\mathrm{g}}(t)$ (in the rearward stage of the transient) current components [5, 8]. These components and their sum are described as

$$
\begin{aligned}
& i(t)=i_{\mathrm{C}}(t)+i_{\mathrm{g}}(t)=A C_{\mathrm{b} 0} \frac{1+\frac{U_{C}(t)}{2 U_{\mathrm{bi}}}}{\left[1+\frac{U_{\mathrm{C}}(t)}{U_{\mathrm{bi}}}\right]^{3 / 2}} \\
& +\frac{q_{\mathrm{e}} n_{\mathrm{i}} S w_{0}}{\tau_{\mathrm{g}}}\left[1+\frac{U_{\mathrm{C}}(t)}{U_{\mathrm{bi}}}\right]^{1 / 2} .
\end{aligned}
$$

Here, $A=U_{\mathrm{p}} / \tau_{\mathrm{PL}}$ is the ramp of the LIV pulse with peak value $U_{\mathrm{p}}$ and duration $\tau_{\mathrm{PL}}, U_{\mathrm{bi}}$ is the built-in potential, $U_{C}(t)=A t$ is the applied voltage which increases linearly with time, $q_{e}$ denotes the elementary charge, $n_{i}$ is the intrinsic carrier density, $S$ is an area of the junction and $w_{0}=\left(2 \varepsilon \varepsilon_{0} U_{\mathrm{bi}} / q_{\mathrm{e}} N_{\mathrm{D}}\right)^{1 / 2}$ is the equilibrium depletion width dependent on dopant density $N_{\mathrm{D}}, \varepsilon$ and $\varepsilon_{0}$ are dielectric permittivity of the material and vacuum, respectively.

Variations of barrier capacitance and generation current as a function of neutron fluence are illustrated in Fig. 1 (b). The value of barrier capacitance decreases
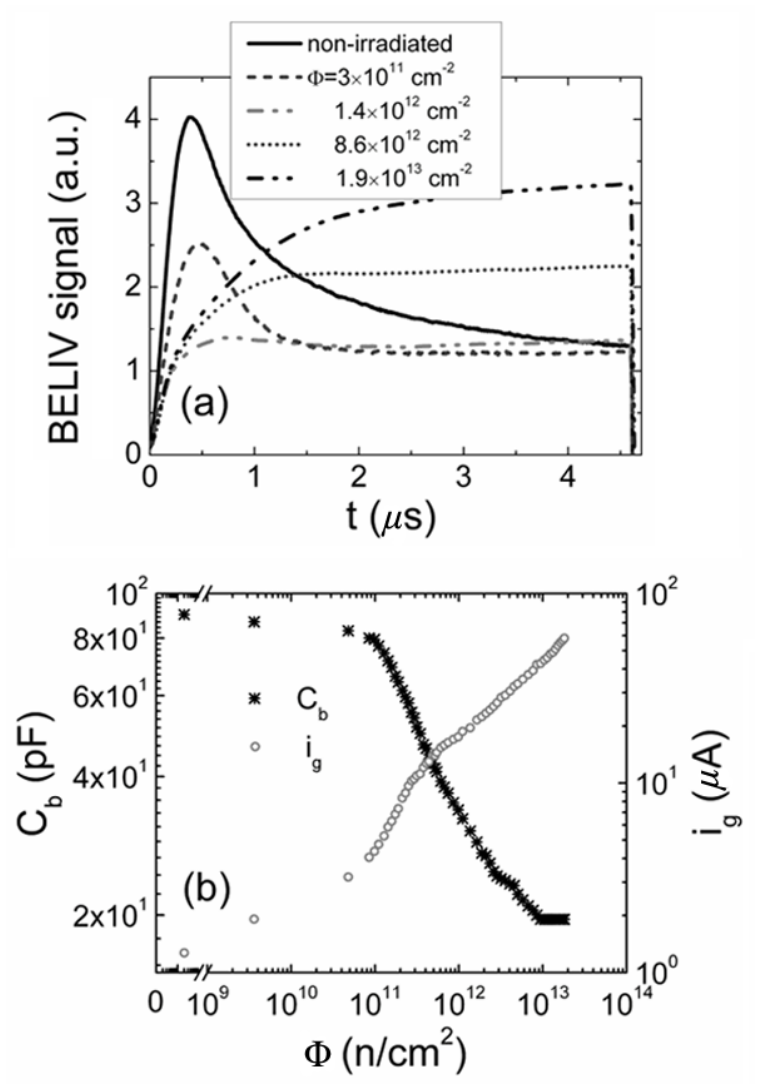

Fig. 1. BELIV transients (a) and variations of barrier capacitance and generation current (b) measured in situ on Si pin diodes during spallator neutron irradiation. 
with enhancement of fluence and reaches its geometrical value at the fluence $\Phi \geq 10^{13} \mathrm{~cm}^{-2}$. A reduction of barrier capacitance appears due to the carrier capture by radiation defects. Meanwhile, the generation current increases with enhancement of the neutron irradiation fluence. The generation current becomes the dominant component at fluences $\Phi>10^{12} \mathrm{~cm}^{-2}$.

Spectroscopy and identification of the prevailing radiation defects under neutron fluences above $10^{14} \mathrm{~cm}^{-2}$ have been performed after irradiation by temperature scans. This range of fluences is important to predict operational characteristics of the future detectors for the high luminosity colliders.

An enhancement of the generation current component (determined by traps of certain activation energy) in BELIV transients is observed when the duration of the LIV pulse is close to the carrier thermo-emission lifetime. This peculiarity has been employed for the ex situ measurements of the temperature dependent variations of BELIV transients by varying duration of the LIV pulses. The obtained temperature dependent variations of BELIV transients for the fixed irradiation fluence (a) and extracted generation current (b) for diodes irradiated with different fluences are presented in Fig. 2. The activation energy values of $0.18 \pm 0.01$, $0.26 \pm 0.02$, and $0.40 \pm 0.02 \mathrm{eV}$ have been evaluated for the dominant traps, and these traps are ascribed to the vacancy-oxygen $(\mathrm{VO})$ and divacancy $\left(\mathrm{V}_{2}\right)$ type defects, respectively, using literature data of deep level signatures [10]. It has been unveiled that the higher irradiation fluence in the deeper levels prevails in the formation of the generation current.

The temperature dependent MW-PC transients have been additionally examined on the reactor neutrons irradiated n-type $\mathrm{Si}$ wafer samples in the fluence range of about $10^{14} \mathrm{~cm}^{-2}$. The carrier recombination and trapping lifetime values as a function of the inverse thermal energy (extracted from the measured MW-PC transients) are plotted in Fig. 3, as obtained for the samples irradiated with the fluence of $10^{14} \mathrm{~cm}^{-2}$. Carrier decay transients for the as-irradiated samples appear to be the single-exponential waveform. However, these transients are transformed into the two-componential decays after anneals.

The two-componential decay manifests that the relaxation process of excess carrier density is governed by a two-centre system, one of which has close values of the capture cross-section for electrons and holes, while another defect traps only single-type carriers. Conventionally such a process is described by the instantaneous trapping lifetime [11]:

$$
\tau_{\mathrm{tr}}=\tau_{\mathrm{R}}\left[1+M N_{\mathrm{M}} /\left(N_{\mathrm{M}}+\Delta n\right)^{2}\right]
$$
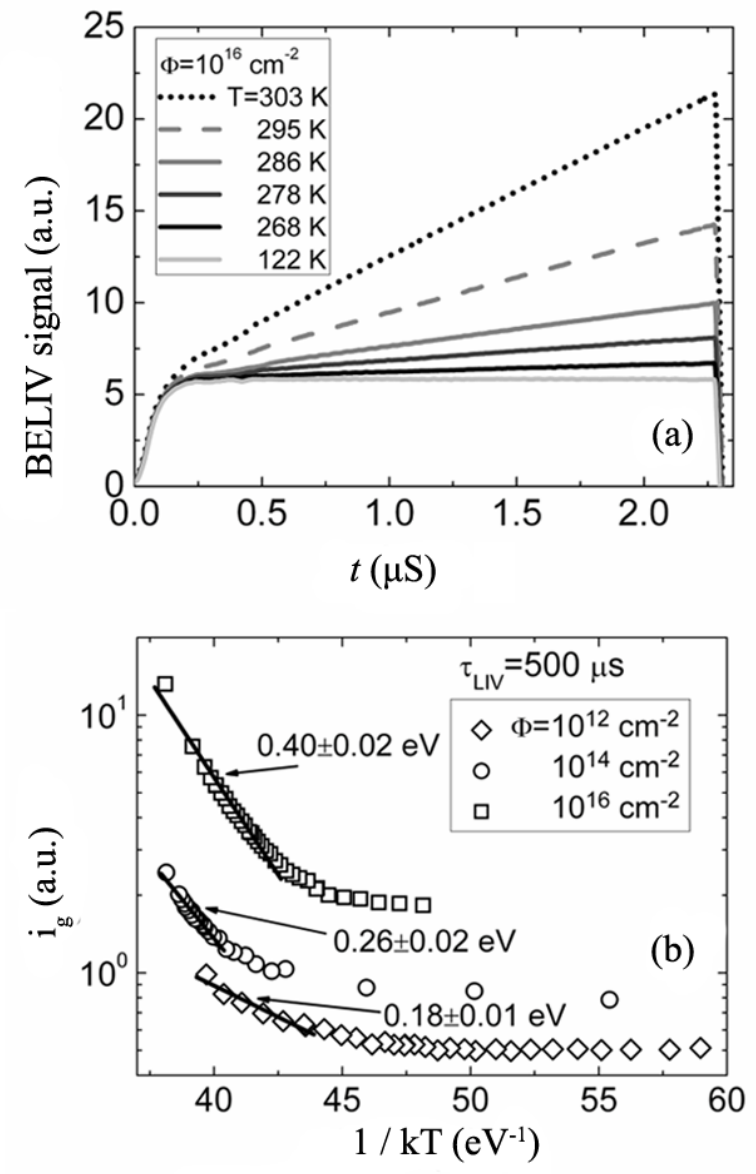

Fig. 2. (a) Temperature dependent BELIV transients measured on a pin diode irradiated by reactor neutrons at the fluence $\Phi=10^{16} \mathrm{~cm}^{-2}$. (b) Generation current variations versus inverse temperature measured on pin diodes irradiated by reactor neutrons of different fluences.

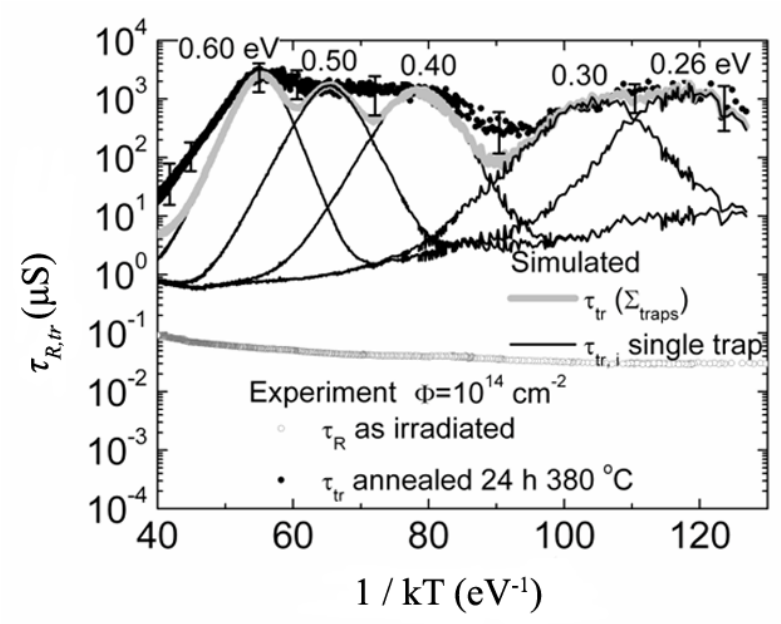

Fig. 3. Temperature dependent carrier recombination $\tau_{\mathrm{R}}$ and trapping $\tau_{\mathrm{tr}}$ lifetime variations in reactor neutrons as irradiated at fluences $\Phi=10^{14} \mathrm{~cm}^{-2}$ and annealed $\mathrm{Si}$ wafer samples. 
Here, $\tau_{\mathrm{R}}$ is a recombination lifetime described by the Shockley-Read-Hall (S-R-H) model with the wellknown dependencies on the excess carrier density $\Delta n$ and temperature $T$. The single-type carrier trapping is determined by the concentration $M$ of such type defect and the effective density of states reduced by the trap activation factor $N_{M}=N_{C, V} \exp \left(-\Delta E_{M} / k T\right)$. Spectroscopy by using the trapping effect is namely based on temperature dependent changes of the carrier lifetime through variations of the effective density of states (i. e. $N_{M}(T)$ ). Hereby, trapping increases during the relaxation process of $\Delta n$, since the excess carrier density falls down, and the trapping effect appears as a long-tail component within the MW-PC transients at relatively low excitation intensity. Also, excess carrier density $\Delta n=\alpha(T) I_{\text {ex }}$ decreases with temperature due to variation of the absorption coefficient $\alpha(T)$ at excitation wavelength $\lambda$ with the surface excitation quanta flow of $I_{\text {ex }}$ and $\alpha(T)=\alpha(T=300 \mathrm{~K})(T / 300 \mathrm{~K})^{4.25}$ at $\lambda=1062 \mathrm{~nm}$ if the excitation light intensity is kept invariant. It can be deduced from Eq. (2) that the instantaneous trapping lifetime depends on temperature as $\tau_{\mathrm{tr}}\left(\Delta E_{M}, T\right) \sim$ $\exp \left(-\Delta E_{\mathrm{M}} / k T\right)$ for $\Delta n \geq N_{\mathrm{M}}$. This trapping lifetime dependence becomes $\tau_{\text {tr }}\left(\Delta E_{M}, T\right) \sim \exp \left(\Delta E_{M} / k T\right)$ for $\Delta n<N_{\mathrm{M}}$. This yields the formation of a peak in the lifetime $\tau_{\text {tr }}\left(\Delta E_{M}, T\right)$ temperature scan, as the density of trapped carriers is varied with temperature.

This formation of the trapping lifetime peaks within the temperature scan can serve as the indication of the transforms of radiation defects. There a system of the simultaneously acting carrier trapping $\tau_{\text {tr }}$ and recombination $\tau_{\mathrm{R}}$ centres is considered. The deep traps act as the recombination defects, while carriers are temporary captured on levels which act as the trapping (generation current) centres. The competition of these centres determines the carrier decay flows and the current components in diode structures. The carrier lifetime $\left(\tau_{\mathrm{R}}\right.$ as well as $\left.\tau_{\mathrm{tr}}\right)$ dependences on the inverse thermal energy $(1 / k T)$ have been employed for evaluation of activation energy of radiation defects. The trapping centres with the activation energy values of $E_{\mathrm{tr} 1}=0.60 \pm 0.03, E_{\mathrm{tr} 2}=0.50 \pm 0.02, E_{\mathrm{tr} 3}=0.40 \pm 0.02$, $E_{\mathrm{tr} 4}=0.30 \pm 0.02$, and $E_{\mathrm{tr} 5}=0.26 \pm 0.02 \mathrm{eV}$ should be employed to fit the experimental trapping lifetime changes within the temperature scan for the diode irradiated with neutron fluence $\Phi=10^{14} \mathrm{~cm}^{-2}$ and annealed at $380^{\circ} \mathrm{C}$. Here, a pedestal of the simulated peaks is the variation of the measured recombination lifetime. In Fig. 3, the symbols represent the experimental changes of carrier lifetime values, while the simulated trapping lifetime peaks attributed to a definite level with the characteristic activation energy are shown by lines. There, the grey curve represents the simulated sum over all the acting trapping cen- tres. The overlap of the trapping ascribed peaks in the lifetime temperature scans $\left(\tau_{\text {tr }}-1 / k T\right)$ can be noticed in Fig. 3. De-convolution of the $\tau_{\mathrm{tr}}-1 / k T$ bands enabled us to distinguish the centres with the activation energy values of $E_{\mathrm{tr} 1}=0.60 \pm 0.03, E_{\mathrm{tr} 2}=0.50 \pm 0.02$, and $E_{\mathrm{tr} 4}=0.30 \pm 0.02 \mathrm{eV}$ ascribed in literature to the radiation clusters [10] and $E_{\mathrm{tr} 3}=0.40 \pm 0.02$ and $E_{\mathrm{tr} 5}=0.26 \pm 0.02 \mathrm{eV}$ [1, 2] commonly attributed to the single- and double-charged divacancy $\left(V_{2}^{-/ 0}, V_{2}^{=/-}\right)$, respectively. It can be deduced by comparing the extracted deep level activation energy values that the divacancies appear as the most efficient carrier trapping centres, which determine the generation current in the diode. Additionally, the thermal treatment activates a rich spectrum of traps. In the as-irradiated material, the cluster defects are the dominant recombination centres, while these defects can act as the single-type carrier capture levels with large cross-sections under anneal induced defect transforms.

The unveiled rich spectrum of traps is also a reason for the reduction of the barrier capacitance of rather heavily neutron irradiated diodes made of the large resistivity Si material. Conductivity carriers supplied by the shallow dopants of a rather small density are rapidly captured by radiation defects with concentrations considerably exceeding that of doping. Then, the base region of a diode becomes a fully depleted layer to support the $U_{\mathrm{bi}}$ barrier, and it acts as an extremely large resistivity structure. As a result, the generation current dominates in such a heavily irradiated detector.

\section{Summary}

A combined study of temperature dependent generation current and carrier recombination and trapping components within MW-PC transients is an effective tool for the in situ and ex situ spectroscopy of radiation defects. These combined techniques are preferential when standard methods such as DLTS are non-applicable due to a large density of traps which significantly exceeds that of doping. It has been revealed that the barrier capacitance charging current component decreases while the generation current component increases within the pulsed current transient generated by linearly increasing voltage applied on the diode, with enhancement of spallator neutron fluence. An analysis of temperature dependent generation current and carrier lifetime allowed us to evaluate the activation energy of carrier recombination and trapping centres. The trapping centres with the activation energy values of $E_{\mathrm{tr} 1}=0.60 \pm 0.03, E_{\mathrm{tr} 2}=0.50 \pm 0.02$, and $E_{\mathrm{tr} 4}=0.30 \pm 0.02 \mathrm{eV}$, ascribed to the radiation clusters, and $E_{\mathrm{tr} 3}=0.40 \pm 0.02$ and $E_{\mathrm{tr} 5}=0.26 \pm 0.02 \mathrm{eV}$, attributed 
to the single- and double-charged divacancy $\left(V_{2}^{-10}\right.$, $V_{2}=/-$ ), have been distinguished by the analysis of the MW-PC trapping lifetime. The activation energy values of $0.18 \pm 0.01,0.26 \pm 0.02$, and $0.40 \pm 0.02 \mathrm{eV}$ of the prevailing carrier generation centres have been evaluated by the BELIV technique. These traps are ascribed to the vacancy-oxygen ( $\mathrm{VO}$ ) and divacancy $\left(\mathrm{V}_{2}\right)$ defects, respectively.

\section{Acknowledgements}

This study was funded by the European Social Fund under the Global Grant measure project VP1-3.1ŠMM-07-K-03-010.

\section{References}

[1] H. Spieler, Semiconductor Detector Systems (Oxford University Press, New York, 2005).

[2] G. Lutz, Semiconductor Radiation Detectors - Device Physics (Springer, Heidelberg, 2007).

[3] E. Gaubas, T. Čeponis, and J. Vaitkus, Impact of generation current on evaluation of the depletion width in heavily irradiated Si detectors, J. Appl. Phys. 110, 033719 (2011).

[4] E. Gaubas, T. Ceponis, A. Jasiunas, A. Uleckas, J. Vaitkus, E. Cortina, and O. Militaru, Correlated evolution of barrier capacitance charging, genera- tion and drift currents and of carrier lifetime in $\mathrm{Si}$ structures during $25 \mathrm{MeV}$ neutrons irradiation, Appl. Phys. Lett. 101, 232104:1-232104:3 (2012).

[5] E. Gaubas, T. Ceponis, J. Kusakovskij, and A. Uleckas, Barrier evaluation by linearly increasing voltage technique applied to Si solar cells and irradiated pin diodes, ISRN Mater. Sci., Article ID 543790 (2012).

[6] E. Gaubas, Transient absorption techniques for investigation of recombination properties in semiconductor materials, Lith. J. Phys. 43, 145-165 (2003).

[7] S. Vayrynen, P. Tikkanen, J. Raisanen, I. Kassamakov, and E. Tuominen, Effects of activation by proton irradiation on silicon particle detector electric characteristics, J. Appl. Phys. 106, 024908 (2009).

[8] E. Gaubas, T. Čeponis, S. Sakalauskas, A. Uleckas, and A. Velička, Fluence dependent variations of barrier and generation currents in neutron and proton irradiated Si particle detector, Lith. J. Phys. 51, 227-233 (2011).

[9] S. Assouak, E. Forton, and G. Gregoire, Irradiations of CMS silicon sensors with fast neutrons, Nucl. Instrum. Methods A 514, 156 (2003).

[10] M. Huhtinen, Simulation of non-ionizing energy loss and defect formation in silicon, Nucl. Instrum. Methods A 491, 194-215 (2002).

[11]S.M. Ryvkin, Photoelectronic Effects in Semiconductors (Consulting Bureau, New York, 1964).

\title{
RADIACINIŲ GAUDYKLIU SILICYJE SPEKTROSKOPIJA PAGAL FOTOLAIDUMO IR GENERACINĖS SROVĖS TEMPERATÜRINIUS KITIMUS
}

\author{
E. Gaubas, T. Čeponis, J. Pavlov, A. Velička, V. Kalesinskas \\ Vilniaus universiteto Taikomujų mokslu institutas, Vilnius, Lietuva
}

\begin{abstract}
Santrauka
Darbe ištirti Čochralskio būdu (MCZ) magnetiniame lauke išauginto ir neutronais apšvitinto $\Phi \cong 10^{14} \mathrm{~cm}^{-2}$ ittèkiu n-laidumo Si padèklai bei šios Si medžiagos pagrindu pagaminti pin diodai. Tyrimai vykdyti pasitelkiant barjerinès talpos elektrinimo srovių ir mikrobangomis zonduojamo fotolaidumo kinetikų matavimo metodikas. Identifikuoti in situ barjerinès talpos ir generacinès
\end{abstract}

srovès kitimus nulèmusieji radiaciniai defektai, sukurti Si diodiniuose dariniuose apšvitinus spalatoriaus neutronais. Nustatyta, kad barjerinès talpos elektrinimo srovès komponentè mažèja, o generacinès srovès nulemta komponentè auga didèjant neutronu iteèkiui. Analizuojant generacinès srovés ir krūvininkų gyvavimo trukmès temperatūrinius kitimus buvo ịvertintos dominuojančiu gaudyklių aktyvacijos energijos. 